\title{
Evaluation of clearness index and cloudiness index using measured global solar radiation data: A case study for a tropical climatic region of Nigeria
}

\author{
Olanrewaju Olukemi SONEYE
}

Department of Physics, Anchor University Lagos, Nigeria

Email: olanrewaju.soneye@gmail.com; osoneye@aul.edu.ng

Received: November 16, 2019; accepted: February 26, 2020

\begin{abstract}
RESUMEN
En este estudio se utiliza una base de datos de radiación solar de dos años (enero 2016-diciembre 2017) para modelar índices de claridad y nubosidad en Ile-Ife, Nigeria, una localidad tropical. Los análisis de variación diaria mostraron que en la mayor parte de los días la nubosidad es uniforme en el sitio de estudio, con muy pocos días extremadamente claros o nubosos. En el plano mensual, el índice de claridad fluctuó entre 0.27 y 0.51 , en tanto que el índice de nubosidad varió de 0.44 a 0.72 , lo cual confirma que las variaciones en ambos índices son inducidas por cambios en la posición del sol, así como por la turbidez y las nubes. Se observó que las variaciones estacionales de ambos parámetros son inversas, de manera que los incrementos en el índice de claridad favorecidos por cielos despejados y meses sin lluvia corresponden a descensos en los valores del índice de nubosidad y viceversa. Los valores mínimos del índice de claridad ( 0.10 y 0.28 ) en el sitio de estudio fueron mayores al valor mínimo (0.5) establecido para dicho índice en condiciones de nubosidad. Se desarrollaron dos ecuaciones empíricas para calcular el máximo índice de claridad a partir del índice de claridad promedio y el índice de nubosidad a partir del índice de claridad, y se sugiere su uso para locaciones con condiciones climatológicas similares al área de estudio. También se comprobó que los modelos de Hollands y Huget y de Saunier et al. tuvieron un buen desempeño, el cual mejoró en alrededor de 23.62 y $3.66 \%$, respectivamente, después de la calibración, por lo que se consideran adecuados para su uso en otras zonas tropicales.
\end{abstract}

\begin{abstract}
This study uses a two-year dataset (January 2016-December 2017) on global solar radiation to model the clearness and cloudiness indices at Ile-Ife, Nigeria, a tropical location. Analysis of the daily variations showed that most days at the location are uniform in cloudiness, with scarcely any day either extremely cloudy or extremely clear. On a monthly basis, the clearness index ranged from 0.27 to 0.51 , while cloudiness index ranged from 0.44 to 0.72 , confirming that the variations of both ratios are influenced by changes in the position of the sun, turbidity and clouds. The seasonal variations of the two parameters were observed to be inverse, so that increases in the clearness index induced by cloudless sky and dry months correspond to decreases in the cloudiness index values and vice versa. The minimum values $(0.10$ and 0.28$)$ of the clearness index at the location are observed to be higher than the minimum value of 0.05 stipulated for the clearness index in cloudy conditions. Two empirical equations for estimating the maximum clearness index in terms of the average clearness index and the cloudiness index in terms of the clearness index are developed and recommended for other locations with climatological conditions similar to those of the study site. It was furthermore observed from the evaluation of formulated empirical equations that the Hollands and Huget and the Saunier et al. models performed well and improved by about 23.62 and 3.66\%, respectively, after calibration, to make the models suitable for their application at other tropical areas.
\end{abstract}

Keywords: global solar radiation, diffuse solar radiation, clearness index, cloudiness index, tropical climatic region. 


\section{Introduction}

Various atmospheric components attenuate the intensity of extra-terrestrial radiation emissions from the Sun by scattering or absorbing them as they arrive at the top of the Earth's atmosphere and propagate through the atmosphere to the surface. These components include gas molecules (ozone, oxygen, carbon dioxide and water vapor), suspended particulates like aerosols, soot, pollen, haze and smoke, and the reflectivity of clouds (Wallace and Hobbs, 2006; Soneye, 2018). The fraction of the extra-terrestrial radiation that finally gets to the Earth's surface is known as global solar radiation. It makes up the net radiation along with what is called diffuse solar radiation, which is another kind of radiative flux that is produced as incoming solar radiation emissions from the Sun are scattered and reflected in the atmosphere (Babatunde and Aro, 1995; Aruna and Janarthanan, 2014).

The global solar radiation received at any location on Earth can be determined by quantifying meteorological parameters such as the clearness index, cloudiness index, diffuse coefficient and relative sunshine duration hour (Ideriah and Suleman, 1989; Muneer, 1995; Udo, 2000; Li et al., 2004). The clearness index is the ratio of the measured global solar radiation at the Earth's surface to the extra-terrestrial solar radiation at the top of the atmosphere, while the cloudiness index is the ratio of the diffuse solar radiation to the global solar radiation at the Earth's surface. The clearness index describes the attenuation of extra-terrestrial solar radiation by atmospheric components like clouds and aerosols, and thereby measures how transparent the Earth's atmosphere is to solar radiation (Liu and Jordan, 1960; Kuye and Jagtap, 1992; Akhlaque et al., 2009; Augustine and Nnabuchi, 2009; Okogbue et al., 2009; Poudyal et al., 2012). It furthermore determines variations in atmospheric conditions and the availability of solar radiation at any location, theoretically taking its values from an interval of 0 to 1 ; however, it usually varies from about 0.8 in clear sky conditions to near 0 in cloudy conditions. The values of the cloudiness index are almost inverses of those of the clearness index, with low values indicating cloudiness while high values indicate clear sky conditions. The cloudiness index also takes its values from an interval of 0 to 1 , and is usually increased by turbidity, geographical location, reflection coefficient (surface albedo) and relative humidity. It describes the effectiveness of the atmosphere to scatter global solar radiation (Iziomon and Aro, 1998). In terms of the classification of sky conditions, these ratios (clearness and cloudiness index) are widely used due to their dependency on global solar radiation (Muneer, 1995; Li et al., 2004).

Knowing the daily values of the clearness and cloudiness indices is crucial to evaluate the climatological potential of a particular area for its possible exploitation and the utilization of solar energy. Also, information on these ratios is of great importance for the design, construction, development and estimation of the expected values of the output of flat plate collectors, photovoltaic systems and other thermal devices that depend on solar energy (Iqbal, 1983; Iziomon and Aro, 1998; Udo, 2000; Ali et al., 2003; Duffie and Beckman, 2006; Aruna and Janarthanan, 2014). Increased understanding of the potential of certain areas for the use of solar energy through the investigation of global solar radiation, clearness and cloudiness indices is especially relevant for locations in Nigeria and other developing countries that are energy poor (Chidebell-Emordi, 2015).

Since Liu and Jordan (1960) examined the clearness and cloudiness indices for 27 locations around the world with a near five-year dataset, many researchers (Iqbal, 1978; Barbaro et al., 1981; Vignola and McDaniels, 1984; Akuffo and Brew-Hammond, 1993; Babatunde and Aro, 1995; Iziomon and Aro, 1998; Udo, 2000; Babatunde, 2005; Augustine and Nnabuchi, 2009; Okogbue et al., 2009; Falayi and Rabiu, 2011; Jung et al., 2016; Rama et al., 2016) have used these indices to investigate atmospheric conditions in various locations. The results of these works have questioned some of the assumptions of Liu and Jordan (1960) and have shown their models to have limited applicability, especially in the tropical areas.

Liu and Jordan (1960) showed that monthly values of the cloudiness index are a function of the monthly global atmospheric transmissivity. They further concluded that the monthly mean of the clearness index is practically independent of the month and location. However, subsequent works have shown that the behavior of the cloudiness index is not singularly dependent on the clearness index, since the values obtained for the clearness index from the addition of 
the values of suspended atmospheric aerosol particles, air mass, surface reflection coefficient (albedo) and cloudiness may not necessarily result in distinct values for the cloudiness index. Secondly, the studies have further shown that assumptions of Liu and Jordan (1960) (namely, that the relationship between the ratios is independent of clouds and that the variation of the clearness index depend mainly on cloudiness) can barely be applied to tropical areas.

Therefore, various empirical models that can be used for determining hourly, daily and monthly values of the ratios have been formulated over the years by different researchers, with the main purpose of developing models with widespread applicability. These models vary and cannot be readily applied to all areas for issues that include variations in equipment calibration, differences in the spatial and temporal averaging of data and variations in atmospheric conditions and climatological patterns (Iziomon and Aro, 1998; Aruna and Janarthanan, 2014). Both the Hollands and Huget (1983) and the Saunier et al. (1987) models have been used to examine the clearness index and atmospheric conditions of tropical areas like Ibadan and Ilorin in Nigeria and Kumasi in Ghana. This paper focuses on evaluating and validating the models for another area of Nigeria with the objective of increasing the knowledge of the wider applicability of the two models to investigate atmospheric conditions in tropical areas.

This study determines the daily, monthly and annual variations of the clearness index and the cloudiness index at Ile-Ife, Nigeria. It examines the relationship between the values for the indices in the area and evaluates and validates the Hollands and Huget (1983) and Saunier et al. (1987) models. Additionally, it develops empirical equations that can be used for estimating the maximum clearness index in terms of the average clearness index and the cloudiness index in terms of the clearness index at other locations where only the global solar radiation flux is measured.

\section{Methodology}

The global solar radiation two-year dataset (January 2016-December 2017) used in this study to estimate the daily average of clearness and cloudiness indices was obtained from a meteorological station located in the Teaching and Research Farm, Obafemi Awolowo University, Ile-Ife, Nigeria. The measurements of global solar radiation were made with a pyranometer (type SR01, ISO-class) facing upward, contained in a four-component net radiometer (model NR01, Hukseflux, USA) sensor, and a datalogger and storage module data acquisition system (model CR1000, Campbell Scientific, USA). Detailed description of the instrumentation and measurement site where the dataset used in this study were acquired can be found in Soneye et al. (2019). The dataset was divided into two annual sets. The daily values of the clearness index for the study site were calculated using:

$$
C_{t}=\frac{S_{\downarrow}}{S_{0}}
$$

where $S_{\downarrow}$ is the measured global solar radiation and $S_{0}$ is the daily extra-terrestrial solar radiation at the top of the atmosphere calculated using the following mathematical expression (Iqbal, 1983; Duffie and Beckham, 2006):

$$
\begin{aligned}
S_{0}= & \frac{24 \times 3600}{\pi} \times G_{0} \times E_{0} \times \\
& \left(\sin \omega_{s} \cos \phi \cos \delta+\frac{\pi \omega_{s}}{180} \sin \phi \sin \delta\right)
\end{aligned}
$$

where $G_{0}$ is the solar constant $=1367 \mathrm{Wm}^{-2}, E_{0}$ is the eccentricity correction factor of the Earth's orbit, $\phi$ is the latitude (positive north), $\omega_{s}$ is the sunrise hour angle, $\delta$ is the solar declination angle and $\pi=3.142$. The units of $\phi$, and $\delta$ are degrees.

The solar declination angle was determined using the equation developed by Cooper (1969):

$\delta=\phi_{L} \sin \left[\frac{2 \pi\left(d_{n}-d_{r}\right)}{d_{y}}\right]$

where $\phi_{L}$ is the latitude of the Tropic of Cancer $\left(23.45^{\circ} \mathrm{N}\right), d_{n}$ is the Julian day number of the year (DOY), which ranges from 1 on 1 January to 365 on 31 December, $d_{r}=284$, and $d_{y}$ is the average number of days per year with a value of 365 .

The eccentricity correction factor was calculated using Spencer (1971) and Iqbal (1983):

$$
\begin{aligned}
& E_{0}=1.000110+0.034221 \cos \Gamma+ \\
& 0.001280 \sin \Gamma+0.000719 \cos 2 \Gamma+ \\
& 0.000077 \sin 2 \Gamma
\end{aligned}
$$


where $\Gamma$ (unit in radians) is the day angle and can be expressed as:

$\Gamma=\frac{2 \pi\left(d_{n}-1\right)}{365}$

The sunrise hour angle was evaluated using:

$\omega_{s}=\cos ^{-1}(-\tan \phi \tan \delta)$

The day length hour was estimated using:

$N_{0}=\frac{2}{15} \cos ^{-1}(-\tan \phi \tan \delta)$

The daily values of the cloudiness index for the study site were calculated using (8) when $\omega_{s}>81.4^{\circ}$ and $0.3 \leq C_{t A V G} \leq 0.8$ (Duffie and Beckham, 2006):

$$
\begin{aligned}
C_{d}=\frac{S_{d}}{S_{\downarrow}}= & 1.311-3.022 C_{t A V G}+ \\
& 3.427 C_{t A V G}{ }^{2}-1.821 C_{t A V G}{ }^{3}
\end{aligned}
$$

where $S_{d}$ is the diffuse solar radiation and $C_{t A V G}$ is the averaged value of the cleanness index.

The empirical models proposed by Hollands and Huget (1983) (9) and Saunier et al. (1987) (10) relating the maximum values of the clearness index $\left(C_{t M A X}\right)$ with the averaged values of this index, were evaluated using the statistical criteria listed in Table I.

$$
C_{t M A X}=0.6313+0.267 C_{t A V G}-11.9\left(C_{t A V G}-0.75\right)^{8}
$$

$C_{t M A X}=0.362+0.59 C_{t A V G}$

The models were estimated using the dataset from January to December 2016 while the estimated equations were validated using the dataset from January to December 2017. The calibration was made using the coefficients of the intercept $a$ (the $x$-value or $y$-value of the point where a line crosses the $x$-axis or $y$-axis, respectively) and slope $b$ (a measure of the steepness

Table I. Statistical criteria for evaluating the performances of the empirical models.

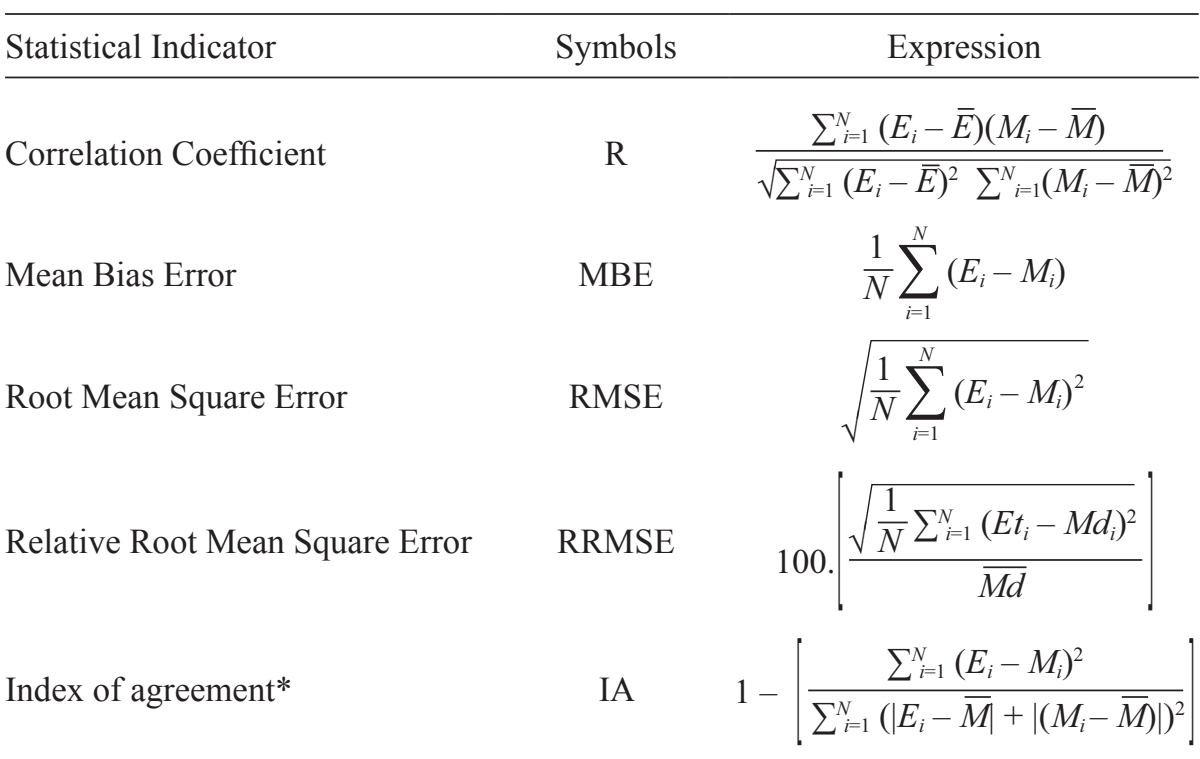

$E$ : estimated flux; $M$ : measured flux; : mean of the measured flux; $N$ : number of observations.

*The index of agreement is a descriptive, bounded and relative tool used for crosscomparison between empirical models. It can be defined as the ratio of the mean square error and the potential error multiplied by the number of observations, and then subtracted from one (Willmott, 1982). The value of the index of agreement varies between 0 and 1 , with higher index values indicating better agreement between the estimated and the measured values. 
of a line), obtained from the linear regression analysis between the measured and estimated values according to Ghamarnia et al. (2012), as expressed in (11):

$C_{\text {tAVG CALIBRATED }}=\frac{C_{t A V G}-a}{b}$

Furthermore, two equations for estimating the cloudiness index were developed using the relationship between the clearness and cloudiness indices by carrying out linear and polynomial regressions between the daily averages of both indices for 2016 . The developed linear and polynomial equations were tested using the dataset from January to December 2017.

\section{Results and discussion}

\subsection{Daily variation of the clearness and cloudiness} indices

The variations in the daily averages of the clearness index for the two-year period (2016-2017) are presented in Figure 1, while Figure 2 shows the same information for the cloudiness index. Figure 1 shows that variations in the clearness index during the two years are bimodal and less pronounced in the dry months (November-February) when compared to the transition months on the dry to wet season (March and April) and to wet months (May-October). As shown in the both figures, the values of the clearness index in 2016 ranged between 0.33 and 0.62 in the dry months while the values in the transition and wet months vary between $0.21-0.63$ and $0.13-0.64$, respectively. For 2017 , the values ranged from $0.16-0.63,0.23-0.61$ and 0.10-0.61 for the dry, transition and wet months, respectively. The average value for 2016 is 0.44 , while it is slightly lower for 2017 (0.42). The highest value (0.64) was recorded on DOY 137 in 2016. Also, higher values for the clearness index were recorded on some days during the wet and cloudy months, corresponding to values observed in the dry months and clear sky days. This is due to rainfall's removal and washout of dust aerosol particles suspended in the atmosphere, which consequently led to lower cloudiness in the atmosphere (Udo, 2000).

The occurrence of very clear skies with $C_{t} \geq 0.65$ is rare in the study area. As presented in Table II, only 13 days with $C_{t} \geq 0.60$ were found in the observation period (2016-2017). Of these, seven occurred in the
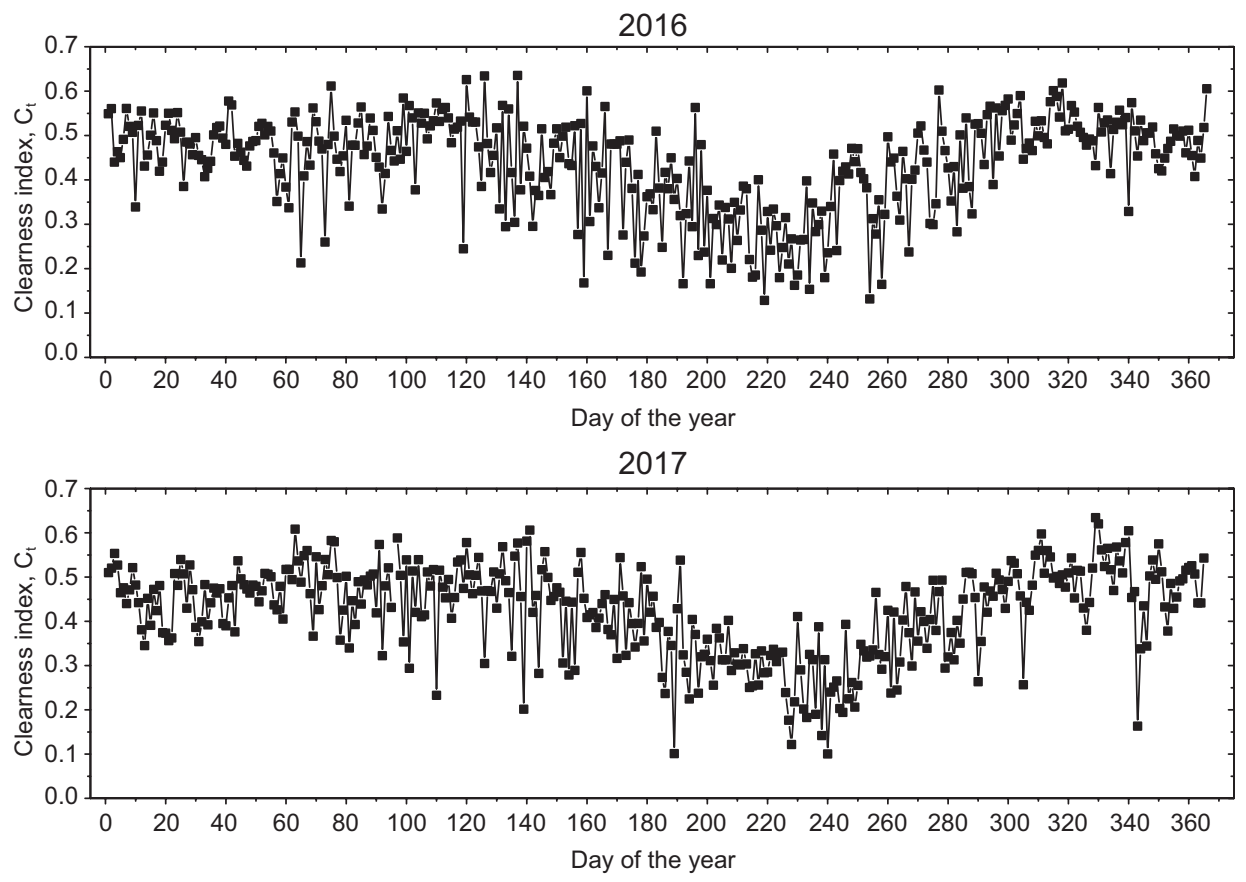

Fig. 1. Daily variations of of the clearness for January 2016 to December 2017 at Ile-Ife, Nigeria. 

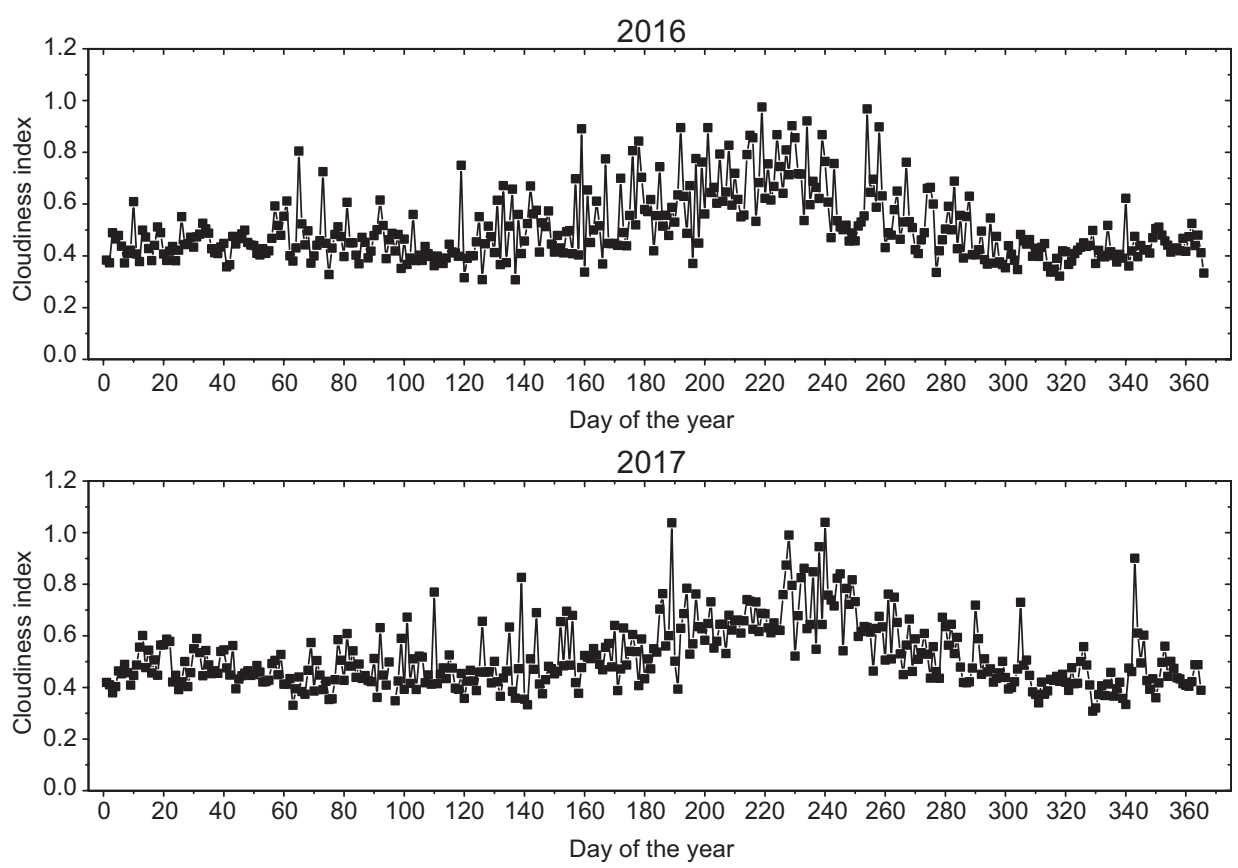

Fig. 2. Daily variation of the cloudiness index for January-December 2016 and January-December 2017 at Ile-Ife, Nigeria

Table II. Number of days of occurrence of clear skies with $C_{t} \geq 0.60$ for January 2016-December 2017 at IleIfe, Nigeria.

\begin{tabular}{|c|c|c|c|}
\hline \multicolumn{4}{|c|}{$C_{t} \geq 0.60$} \\
\hline \multicolumn{2}{|c|}{2016} & \multicolumn{2}{|c|}{2017} \\
\hline Months & No. of days & Months & No. of days \\
\hline March & 1 & March & 1 \\
\hline April & 1 & May & 1 \\
\hline May & 2 & November & 3 \\
\hline November & 2 & December & 1 \\
\hline December & 1 & & \\
\hline
\end{tabular}

dry months while six were observed in the wet months. As Table III shows, cloudy skies with $0.12<C_{t} \leq 0.34$ are more pronounced, particularly in the wet months (with total number of seven days in the dry months and 156 days in the wet months). Due to the removal of harmattan dust aerosol particles from the atmosphere by wet deposition processes in May, and the presence of few or no clouds and harmattan dust in November (a transition month from wet to dry months), a high occurrence of days with $C_{t} \geq 0.60$ was
Table III. Number of days of occurrence of cloudy skies with $0.12<C_{t} \leq 0.34$ for January 2016-December 2017 at Ile-Ife, Nigeria.

\begin{tabular}{lclc}
\hline \multicolumn{4}{c}{$0.12<C_{t} \leq 0.34$} \\
\cline { 1 - 2 } Months & 2016 & & \multicolumn{2}{c}{2017} \\
\hline January & 1 & January & 1 \\
March & 3 & March & 1 \\
April & 2 & April & 3 \\
May & 4 & May & 4 \\
June & 10 & June & 6 \\
July & 17 & July & 17 \\
August & 26 & August & 30 \\
September & 8 & September & 18 \\
October & 3 & October & 4 \\
December & 1 & November & 1 \\
& & December & 3 \\
\hline
\end{tabular}

found during May and November 2016, and November 2017. The high occurrence of days with $0.12<C_{t}$ $\leq 0.34$ during the wet months (June-September) of both years is as a result of the increase in the amount of clouds, rainfall and atmospheric water content, all 
of which attenuated the global solar radiation (Ayoola et al., 2014; Soneye et al., 2019). The minimum values of the clearness index for the study area was observed to be between 0.10 and 0.28 , which are above the minimum value of 0.05 stipulated for this parameter in cloudy conditions. This result suggests that sky conditions in Ile-Ife are barely cloudy despite the prevalence of harmattan dust and cloudiness in the atmosphere. The results are similar to the findings of Ideriah and Suleman (1989) at Ibadan, Nigeria, Akuffo and Brew-Hammond (1993) at Kumasi, Ghana, and Udo (2000) at Ilorin, Nigeria.

As previously stated, the daily variation in the cloudiness index for the two-year period (2016-2017) is presented in Figure 2. Just as it was for the clearness index, data for the cloudiness index shows the variations in the index to be more pronounced in the wet season when compared with values recorded in the dry season. However, in contrast to the clearness index, a minimum of 0.31 and a maximum of 1.04 (recorded on DOY 240 in 2017) were obtained for the cloudiness index. The minimum value obtained shows that the diffuse radiation reaching the Earth's surface is primarily a result of the molecular scattering and, to a lesser extent, of the surface reflection coefficient (albedo) (Iziomon and Aro, 1998). In 2016 the values of the cloudiness index varied from 0.32-0.69 in the dry months and from $0.31-0.98$ in the wet months, while in 2017 the values range between $0.31-0.90$ and $0.33-1.04$ for the dry and wet months, respectively. The high values recorded for the cloudiness index imply that sky conditions at IleIfe are highly cloudy, in contrast to the conclusion drawn from the clearness index.

\subsection{Annual variation of the clearness and cloudi- ness indices}

The monthly variations of both the clearness and cloudiness indices are presented in Table IV. For the years 2016 and 2017, the maximum value for the clearness index was recorded in November while the minimum value was recorded in August. The mean values of about 0.44 and 0.43 were recorded for 2016 and 2017, respectively, while an average value of 0.43 was recorded for the two years. Although slightly lower, these mean values are similar to the 0.47 values obtained in Ibadan $\left(7.45^{\circ} \mathrm{N}\right)$ between $1975-1980$ by Ideriah and Suleman (1989), 0.48 in Ilorin $\left(8.33^{\circ} \mathrm{N}\right)$ for 1993-1994 by Udo (2000) and 0.43 reported by both Awachie and Okeke (1988) in Nsukka, Nigeria and Akuffo and Brew-Hammond (1993) in Kumasi, Ghana. For the cloudiness index, the maximum value for the two years (2016-2017) was recorded in August while the minimum value was recorded in December 2016 and November 2017, respectively. An average value of about 0.52 was recorded for the two years.

The annual variations of the clearness and cloudiness indices for the two years is presented in Figure 3. It can be seen that the variations of the two parameters are inversely related, such that as the

Table IV. Monthly averages of the clearness and cloudiness indices for January 2016-December 2017 at Ile-Ife, Nigeria.

\begin{tabular}{lccccc}
\hline \multirow{2}{*}{ Months } & \multicolumn{2}{c}{2016} & & \multicolumn{2}{c}{2017} \\
\cline { 2 - 3 } \cline { 5 - 6 } & Clearness index & Cloudiness index & & Clearness index & Cloudiness index \\
\hline January & 0.49 & 0.44 & 0.45 & 0.48 \\
February & 0.47 & 0.46 & & 0.46 & 0.47 \\
March & 0.47 & 0.43 & 0.49 & 0.45 \\
April & 0.50 & 0.48 & 0.47 & 0.47 \\
May & 0.45 & 0.55 & 0.47 & 0.47 \\
June & 0.40 & 0.62 & 0.41 & 0.52 \\
July & 0.34 & 0.72 & 0.33 & 0.63 \\
August & 0.27 & 0.56 & 0.27 & 0.72 \\
September & 0.39 & 0.56 & 0.43 & 0.63 \\
October & 0.47 & 0.46 & 0.50 & 0.50 \\
November & 0.52 & 0.41 & 0.48 & 0.43 \\
December & 0.49 & & &
\end{tabular}




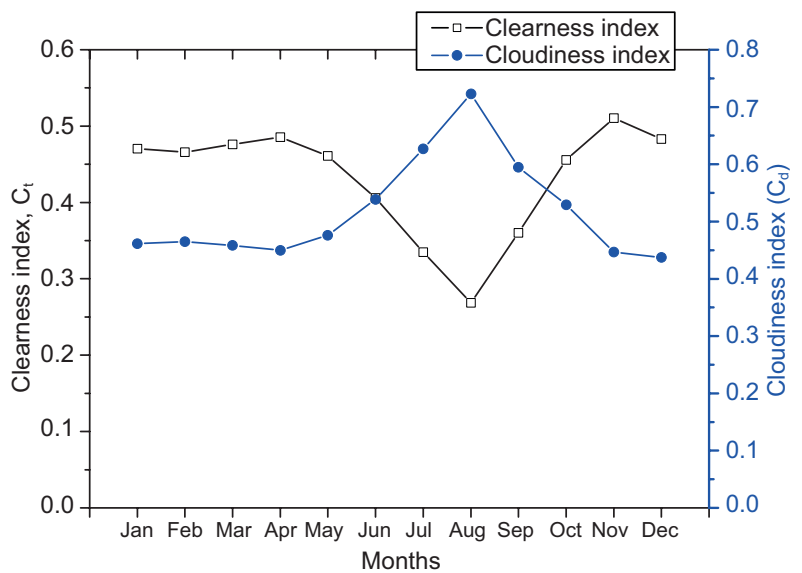

Fig. 3. Annual variations of the clearness and cloudiness indices for January 2016-December 2017 at Ile-Ife, Nigeria.

value of the clearness index increases the value of the cloudiness index decreases and vice versa. The values of these parameters also show strong seasonal variations with a peak value of 0.51 in November for the clearness index and a peak value of 0.72 in August for the cloudiness index. The highest value recorded for the clearness index in November implies that the global solar radiation received at the Earth's surface consists mainly of the beam (direct) radiation component. As a result, the performance of solar energy systems at the location under study are expected to be high in November (Iziomon and Aro, 1998).

The highest monthly mean value for the cloudiness index was obtained in August, which is a wet and cloudy month typically characterized by considerable increase in atmospheric water content and increased number and types of clouds (Ayoola et al., 2014; Soneye et al., 2019). During wet months, the global solar radiation received on a horizontal surface consists mainly of diffuse radiation, which arises majorly from the intense forward scattering of global solar radiation mainly by altostratus, thin cirrus and altocumulus clouds (Iziomon and Aro, 1998; Okogbue et al., 2009). From November to April (when there is no or little cloudiness and a decrease in turbidity when the atmosphere is relatively clear) the values of the clearness index increased, similarly to the results obtained by Babatunde and Aro (1995), Iziomon and Aro (1998) and Udo (2000) in Ilorin, and Okogbue et al. (2009) at Ile-Ife. Furthermore, it was observed that the distribution of both indices is bell-shaped between the months of July and September with a peak for the cloudiness index and a depression for the clearness index in August. This bell-shaped distribution for both ratios has been previously observed at tropical locations by Ideriah and Suleman (1989) and Okogbue et al. (2009).

\subsection{Empirical relation between the maximum and average clearness index}

The monthly variations of the maximum clearness index that was measured and estimated from the Hollands and Huget (1983) and Saunier et al. (1987) models shown in (9) and (10) for 2016 are presented in Figure 4. As shown in this figure, the estimated values of the maximum clearness index obtained from both models essentially duplicate the pattern of the measured index, with the lowest values for both the measured (0.46) and estimated (0.52 and 0.67) variations recorded in the month of August. The highest value of 0.64 was recorded in May for the measured maximum clearness index, while highest estimated values of 0.67 and 0.77 were recorded in November for Saunier et al. (1987) and Hollands and Huget (1983) models, respectively. The values estimated from the models implies that former is more useful in a tropical location than the later (see Fig. 5 for the evaluation performance).

The differences in the measured and estimated values, especially for the Hollands and Huget (1983) model, can be attributed to the differences in the values of the maximum clearness index, geographical location and the fundamental probability density functions between Ile-Ife, on one side, and Bangkok and Canada, where the two models were developed, on the other side. It can also be a result of the differences in intensity of the global solar radiation received at Ile-Ife, Bangkok and Canada. The results are similar to those obtained at Kumasi, Ghana by Akuffo and Brew-Hammond (1993) and at Ilorin, Nigeria by Udo (2000), further supporting the finding that the Saunier et al. (1987) model is more relevant in tropical locations than the Hollands and Huget (1983) model.

The statistical indicators for the original and calibrated models are presented in Figure 5. As shown in this figure, the values of the correlation coefficient 

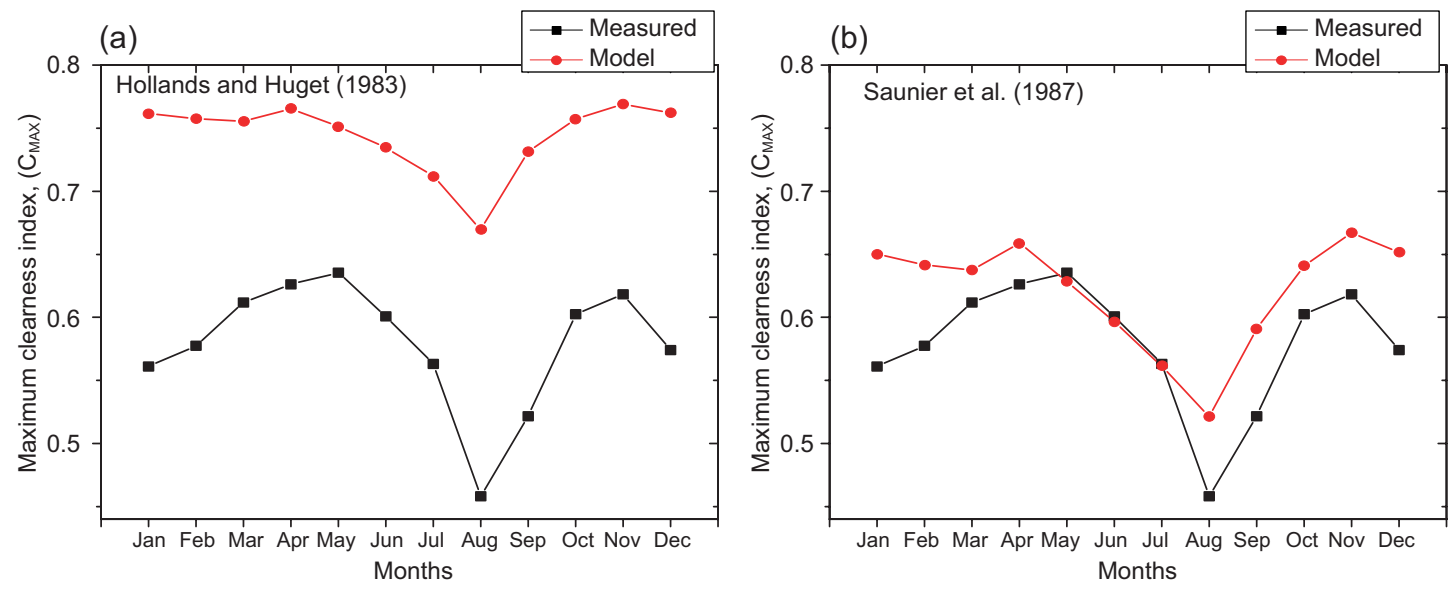

Fig. 4. Monthly variations of the maximum clearness index measured and estimated from Hollands and Huget (1983) and Saunier et al. (1987) models.

and the index of agreement increased after calibration while the values of the errors decreased after calibration, to indicate significant improvements in the models. For the Hollands and Huget (1983) model, the MBE, RMSE and RRMSE values decreased from 0.17 to 0.02 , from 0.17 to 0.03 , and from $28.92 \%$ to $5.34 \%$, respectively; while the values of $\mathrm{R}$ and $\mathrm{d}$ increased from 0.80 to 0.91 and from 0.32 to 0.94 , respectively. For the Saunier et al. (1987) model, the MBE, RMSE and RRMSE decreased from 0.04 to 0.01 , from 0.05 to 0.03 , and from $8.98 \%$ to $5.32 \%$, respectively; while the values of $\mathrm{R}$ and $\mathrm{d}$ increased respectively from 0.76 to 0.91 and 0.72 to 0.95 , respectively. These results are in agreement with those obtained by Udo (2000), who reported that the values of MBE and RMSE were higher for the original Hollands and Huget (1983) and Saunier et al. (1987) models.

The monthly variations of the measured and post-calibration estimated maximum clearness index for 2017 is presented in Figure 6. The highest value of 0.63 was recorded for the measured clearness index in November while the highest values of 0.63 and 0.64 were obtained in the same month for the calibrated Hollands and Huget (1983) and Saunier et al. (1987) models, respectively. In addition, the lowest value of 0.41 was recorded in August for the measured index while the lowest values of 0.41 and 0.43 were estimated in the same month from the respective calibrated Hollands and Huget (1983) and Saunier et al. (1987) models. As these results show, the estimated values of the clearness index improved for both models after the calibration of their original coefficients and are almost the same with the maximum values of the clearness index measured at the study site (see Table V and Fig. 5). The improvements show that despite firstly the Saunier et al. (1987) model was found to be more relevant, both models can be recommended for use in Ife and other tropical areas.

Furthermore, three equations for estimating the maximum clearness index in terms of the average clearness index were developed in this study for the measurement site using linear regression analysis. These equations were developed for both the 2016 and 2017 datasets, and their overall averages are listed below:

$$
C_{t M A X}=0.51 C_{t A V G}+0.36
$$

$$
C_{t M A X}=0.76 C_{t A V G}+0.23
$$

$$
C_{t M A X}=0.65 C_{t A V G}+0.29
$$

Correlation coefficients (R) of about $0.76,0.91$ and 0.89 were obtained for (12), (13) and (14), respectively. These equations, especially (12) and (13), which have higher values of $\mathrm{R}$ in addition to the equations listed in Table V, can be used for estimating the maximum clearness index at tropical areas with similar climatological conditions as Ile-Ife, Nigeria. 
Z7Z Before adjustment $\mathrm{m}$ 带冊 After adjustment
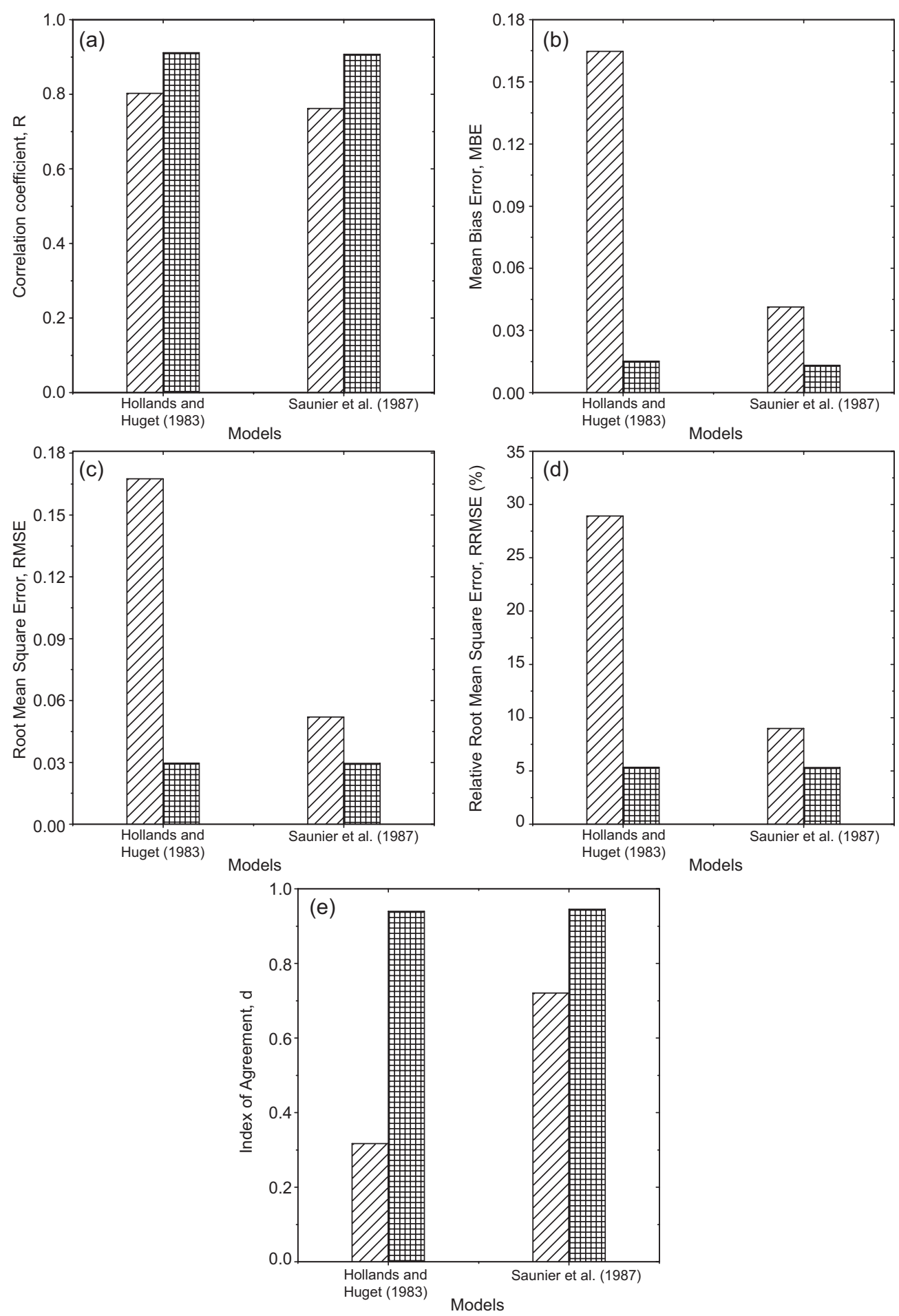

Fig. 5. Statistical measures for the maximum clearness index estimated with the Hollands and Huget (1983) and Saunier et al. (1987) models before and after calibration at Ile-Ife, Nigeria. 

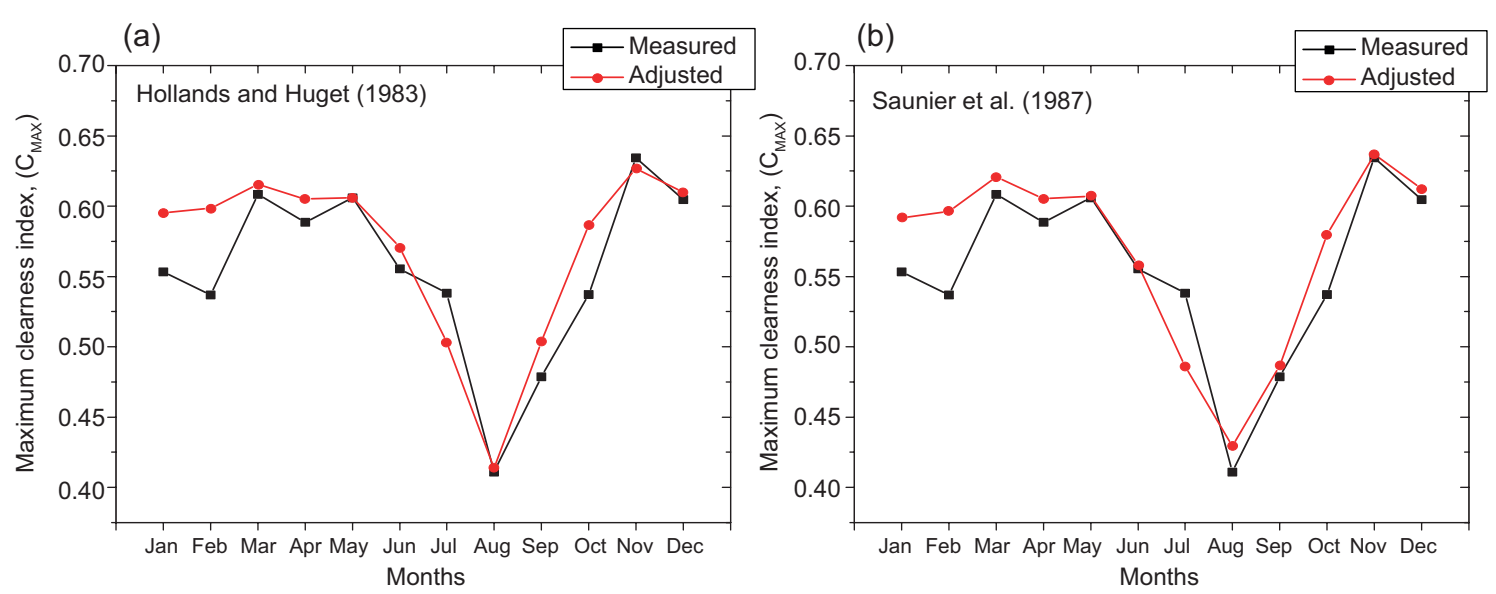

Fig. 6. Monthly variations of the maximum clearness index values, both measured and estimated from the calibrated Hollands and Huget (1983) and Saunier et al. (1987) models.

Table V. Calibrated coefficient of empirical Hollands and Huget (1983) and Saunier et al. (1987) models for Ile-Ife, Nigeria.

\begin{tabular}{|c|c|c|c|}
\hline Model & Calibration constants & & Calibrated equation \\
\hline \multirow[t]{2}{*}{ Hollands and Huget (1983) } & $\frac{0.47713}{0.46059}$ & \multirow{2}{*}{$C_{t M A X}=$} & $\begin{array}{l}{\left[0.6313+0.267 C_{t A V G}-11.9\right.} \\
\left.\left(C_{t A V G}-0.75\right)^{8}\right]-0.47713 \\
\end{array}$ \\
\hline & 0.46059 & & 0.46059 \\
\hline \multirow{2}{*}{ Saunier et al. (1987) } & 0.23057 & \multirow{2}{*}{$C_{t M A X}=$} & {$\left[0.362+0.59 C_{t A V G}\right]-0.23057$} \\
\hline & 0.67325 & & 0.67325 \\
\hline
\end{tabular}

\subsection{Empirical relation between the clearness and cloudiness indices}

Figure 7 shows the linear and polynomial regressions of the relationship between the daily averaged values of the clearness index and the cloudiness index for January-December, 2016. An inverse relationship, which resulted into the simple expression in (15), was observed from the values of these parameters:

$C_{d}+C_{t}=1$

which implies that the value of the cloudiness index will be 0 if the value of the clearness index is 1 and vice versa. Therefore, if $C_{\mathrm{d}}=0$ when $C_{t}=1$, the atmosphere is clear and the amount of direct solar radiation received at the Earth's surface increases due to insignificant attenuation of global solar radiation by clouds and suspended aerosol particles. However, if $C_{d}=1$ when $C_{t}=0$ the case is the converse. The relationship obtained in this study is similar to those

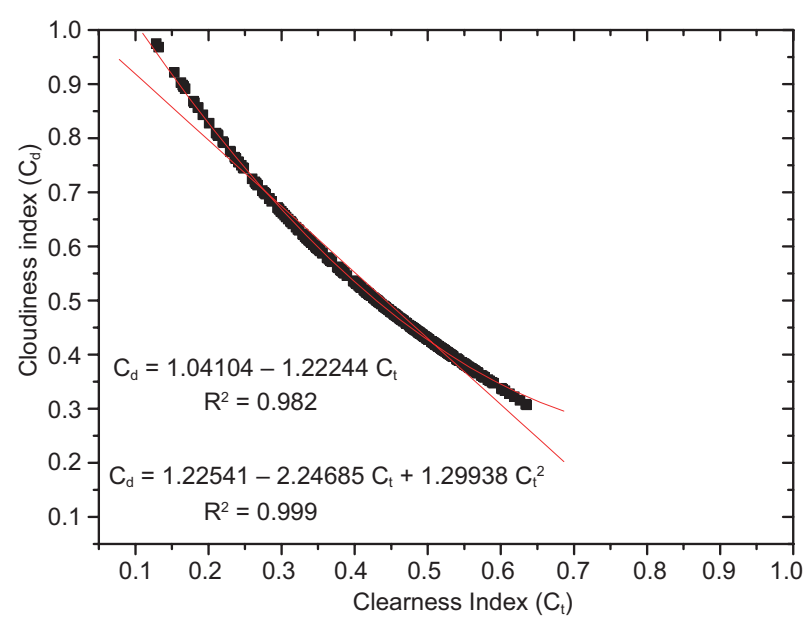

Fig. 7. Correlation between the cloudiness and clearness indices for January-December 2016 at Ile-Ife, Nigeria.

obtained by Babatunde and Aro (1995) at Ilorin, Nigeria and by Aruna and Janarthanan (2014) for three tropical locations (Chennai, Trivandrum and 


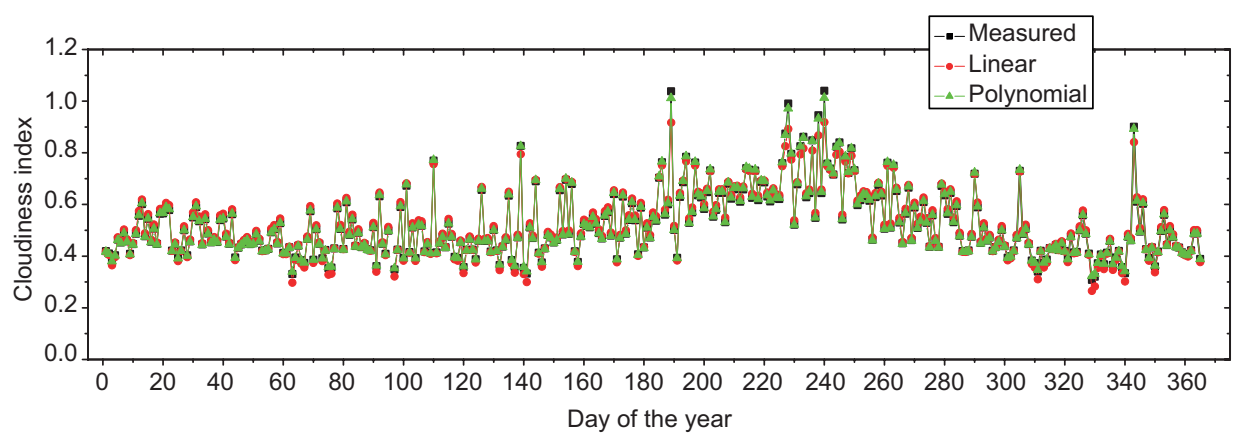

Fig. 8. Daily variations of measured and estimated (linear and polynomial equations) values of the cloudiness index for January-December 2017 at Ile-Ife, Nigeria.

Visakapatnam, India). The linear and polynomial expressions for the cloudiness index as obtained from the regressions of the relationship between the two indices (Fig. 7) are listed respectively in (16) and (17) below:

$C_{d}=1.04104-1.22244 C_{t}$

$C_{d}=1.22541-2.24685 C_{t}+1.29938 C_{t}^{2}$

Figure 8 presents the daily variations of the measured and estimated values of the cloudiness index for 2017 using the linear and polynomial equations listed equations (15) and (16). The results show good agreement between the measured values and the values estimated from the equations. The highest and lowest values of 1.04 and 0.31 , respectively, were recorded for the measured cloudiness index while the corresponding values from the linear equations are 0.92 and 0.27 , and those from the polynomial equation are 1.01 and 0.32 . The good agreement between the maximum and minimum values of both the measured and estimated values of the cloudiness index suggests that, in the absence of measured data at Ile-Ife and other tropical areas with the same surface albedo, climatological and weather conditions, the two equations developed for the cloudiness index can be used for estimating the index.

\section{Conclusions}

The daily, monthly and annual variations of the clearness index and cloudiness index for a two-year (January 2016-December, 2017) period at Ile-Ife, Nigeria has been reported in this paper in order to evaluate the feasibility of using solar energy at this location. The applicability of the Hollands and Huget (1983) and Saunier et al. (1987) models at Ile-Ife, a tropical location, was investigated. Models for estimating the clearness index in terms of the average clearness index, as well as the cloudiness index in terms of the clearness index, were additionally developed.

The major findings and conclusions drawn from this work are the following:

i. The values of the clearness and cloudiness indices at Ile-Ife ranged from 0.10 to 0.64 and from 0.31 to 1.04 , respectively, on a daily basis. On a monthly basis, the values of the clearness index ranged from 0.27 to 0.51 while the cloudiness index ranged from 0.44 to 0.72 , which confirms that the variations of the indices are influenced by changes in the position of the sun, turbidity and clouds.

ii. The clearness index has high values during the dry months (with a peak value of 0.51 in November) and low values in the wet and cloudy months, while the cloudiness index has high values in the wet and cloudy months (with a peak value of 0.72 in August) and low values in the dry months. The low and high values respectively recorded for the clearness index and the cloudiness index in August are attributable to the attenuation of global solar radiation by increased relative humidity and cloudiness. The inverse relationship between the two indices show that in a situation where diffuse solar radiation is not measured, it can be calculated from measured global solar radiation. 
iii. The minimum values of the clearness index for the location lie between 0.10 and 0.28 and thereby higher than the minimum value of 0.05 that is stipulated for the clearness index in cloudy conditions. This shows that sky conditions at IleIfe are barely overcast despite the prevalence of harmattan dust and clouds in the atmosphere of this location, to further show real potentials for the use of solar energy. In addition, most of the days at Ile-Ife are relatively uniform, with hardly any one extremely cloudy or clear. This removes the possibilities of large fluctuations in the utilization of solar energy in the area.

iv. The results further showed that although the empirical expression proposed by Saunier et al. (1987) initially performed better than that proposed by Hollands and Huget (1983) at Ile-Ife, the two equations improved and performed better after calibration. Hollands and Huget (1983) model improved by about $23.62 \%$ while Saunier et al. (1987) model improved by about 3.66\%. This implies that the calibrated Hollands and Huget (1983) and Saunier et al. (1987) expressions as listed in (13) and (14), respectively, are appropriate for the study location and can be recommended for use at other tropical areas.

v. The linear and polynomial empirical expressions relating the cloudiness index to the clearness index as listed in (17) and (18), respectively, showed good agreement between the measured and estimated values. This implies that the two equations are suitable for estimating the maximum clearness index, the cloudiness index and the diffuse solar radiation in terms of the clearness index at Ile-Ife. Thus, the both (17) and (18), which were developed for the cloudiness index at Ile-Ife, can be used for predicting and estimating the index in the absence of measured data at other tropical sites with similar surface albedo, and climatological and weather conditions as Ile-Ife.

\section{Acknowledgments}

The author acknowledges the efforts of Professor Oluwagbemiga Olawale Jegede, the head of the Atmospheric Research Group, Department of Physics and Engineering Physics, Obafemi Awolowo University, Ile-Ife, Nigeria (and other members of the group) in facilitating the setting up of the automated meteorological station. The support of the International Programmes in the Physical Sciences (IPPS), Uppsala University, Sweden and the University of Bayreuth, Germany through equipment donations are also appreciated. The insightful comments and contributions of Dr. Olurotimi Olayemi Soneye on an early draft, which improved the quality of this manuscript is highly appreciated.

\section{References}

Akhlaque AM, Firoz A, Wasim MA. 2009. Estimation of global and diffuse solar radiation for Hyderabad, Sindh, Pakistan. Journal of Basic and Applied Science 5, 73-77.

Akuffo FO, Brew-Hammond A. 1993. The frequency distribution of global solar irradiation at Kumasi. Solar Energy 50, 145-154. https://doi.org/10.1016/0038092X(93)90086-4

Ali A-L, Atsu SSD, Jervase JA. 2003. Monthly average daily solar radiation and clearness index contour maps over Oman. Energy Conversion and Management 44, 691-705s. https://doi.org/10.1016/S01968904(02)00080-8

Aruna RK, Janarthanan B. 2014. Study of clearness and cloudiness index at tropical locations. International Journal of Scientific \& Engineering Research 5, 161169.

Augustine C, Nnabuchi MN. 2009. Correlation of cloudiness index with clearness index for four selected citiesin Nigeria. The Pacific Journal of Science and Technology 10, 568-573.

Awachie IRN, Okeke CE. 1988. Measurement of solar energy radiation at Nsukka and the determination of the regression coefficients. Energy Conversion Management 28, 295-302. https://doi.org/10.1016/01968904(88)90050-7

Ayoola MA, Sunmonu LA, Bashiru MI, Jegede OO. 2014. Measurements of net all-wave radiation at a tropical location, Ile-Ife, Nigeria. Atmósfera 27, 305-315. https:// doi.org/10.1016/S0187-6236(14)71118-X

Babatunde EB, Aro TO. 1995. Relationship between clearness index and cloudiness index at a tropical station (Ilorin, Nigeria). Renewable Energy 6, 801805. https://doi.org/10.1016/0960-1481(94)00087-M

Babatunde EB. 2005. Some solar radiation ratios and their interpretations with regards to radiation 
transfer in the atmosphere. Nigeria Journal of Pure and Applied Physics 4, 41-45. https://doi.org/10.4314/ njpap.v4i1.21465

Barbaro S, Cannata G, Coppilino S, Leone C, Sinagra E. 1981. Diffuse radiation statistics for Italy. Solar Energy 26, 429-435. https://doi.org/10.1016/0038092X(81)90222-X

Chidebell-Emordi E. 2015. The African electricity deficit: Computing the minimum energy poverty line using field research in urban Nigeria. Energy Research \& Social Science 5, 9-19. https://doi.org/10.1016/j. erss.2014.12.011

Cooper PI. 1969. The absorption of solar radiation in solar stills. Solar Energy 12, 333-346. https://doi. org/10.1016/0038-092X(69)90047-4

Duffie JA, Beckman WA. 2006. Solar engineering of thermal processes. John Wiley and Sons. 3rd ed. New York, 37-83.

Falayi EO, Rabiu AB. 2011. Estimation of global solar radiation using cloud cover and surface temperature in some selected cities in Nigeria. Archives of Physics Research 2, 99-109.

Ghamarnia H, Rezvani V, Khodaei E, Mirzaei, H. 2012. Time and place calibration of the Hargreaves equation for estimating monthly reference evapotranspiration under different climatic conditions. Journal of Agricultural Science 4, 111-122. https://doi.org/10.5539/ jas.v4n3p111

Hollands KGT, Huget RG. 1983. A probability density function for clearness index, with applications. Solar Energy 30, 195-209. https://doi.org/10.1016/0038092X(83)90149-4

Ideriah FJK, Suleman SO. 1989. Sky conditions at Ibadan during 1975-1980. Solar Energy 43, 325-330. https:// doi.org/10.1016/0038-092X(89)90102-3

Iqbal M. 1978. Estimation of the monthly average of the diffuse component of total insolation on a horizontal surface. Solar Energy 20, 101-105. https://doi. org/10.1016/0038-092X(78)90149-4

Iqbal M. 1983. An introduction to solar radiation. Academic Press, Toronto, New York, London.

Iziomon MG, Aro TO. 1998. The diffuse fraction of global solar irradiance at a tropical location. Theoretical and Applied Climatology 61, 77-84. https://doi. org/10.1007/s007040050053

Jung Y, Lee H, Kim J, Cho Y, Kim J, Lee YG. 2016. Spatio-temporal characteristics in the clearness index derived from global solar radiation observations in
Korea. Atmosphere 7, 55. https://doi.org/10.3390/ atmos 7040055

Kuye A, Jagtap SS. 1992. Analysis of solar radiation data for Port Harcourt, Nigeria. Solar Energy 49, 139-145. https://doi.org/10.1016/0038-092X(92)90148-4

Li DHW, Lau CCS, Lam JC. 2004. Overcast sky conditions and luminance distribution in Hong Kong. Building and Environment 39, 101-108. https://doi. org/10.1016/j.buildenv.2003.06.001

Liu BYH, Jordan RC. 1960. The interrelationship and characteristic distribution of direct, diffuse and total solar radiation. Solar Energy 4, 1-19. https://doi. org/10.1016/0038-092X(60)90062-1

Muneer T. 1995. Solar irradiance and illuminance models for Japan II: luminous efficacies. Lighting Research and Technology 27, 223-230. https://doi.org/10.1177/ 14771535950270040501

Okogbue EC, Adedokun J.A, Holmgren B. 2009. Hourly and daily clearness index and diffuse fraction at a tropical station, Ile-Ife, Nigeria. International Journal of Climatology 29, 1035-1047. https://doi.org/10.1002/ joc. 1849

Poudyal KN, Bhattarai BK, Sapkota B, Kjeldstad B. 2012. Estimation of global solar radiation using clearness index and cloud transmittance factor at Trans-Himalayan Region in Nepal. Energy and Power Engineering 4, 415-421. https://doi.org/10.4236/epe.2012.46055

Rama GP, Pavan KS, Balakrishnaiah G, Raja ORK, Md. Arafath S, Siva KRN, Chakradhar RT, Lokeswara RT, Reddy RR. 2016. Evaluation of clearness and diffuse index at a semi-arid station (Anantapur) using estimated global and diffuse solar radiation. International Journal of Advanced Earth Science and Engineering 5,: 347-363. Sci-388 ISSN: $2320-3609$

Saunier GY, Reddy TA, Kumar S. 1987. A monthly probability distribution function of daily global irradiation values appropriate for both tropical and temperate locations. Solar Energy 38, 169-177. https:/doi. org/10.1016/0038-092X(87)90015-6

Soneye OO. 2018. Investigation of the effect of atmospheric aerosol loading on the surface radiation balance at Ile-Ife, Southwest Nigeria. Ph.D. thesis. Obafemi Awolowo University, Ile-Ife, Nigeria.

Soneye OO, Ayoola MA, Ajao IA, Jegede OO. 2019. Diurnal and seasonal variations of the incoming solar radiation flux at a tropical station, Ile-Ife, Nigeria. Heliyon 5, e01673. https://doi.org/10.1016/j.heliyon.2019.e01673 
Spencer JW. 1971. Fourier series representation of the position of the Sun. Search 2, 162-172.

Udo SO. 2000. Sky conditions at Ilorin as characterized by clearness index and relative sunshine. Solar Energy 69, 45-53. https://doi.org/10.1016/S0038092X(00)00008-6

Vignola F, McDaniels DK. 1984. Diffuse-global correlation: seasonal variations. Solar Energy 33, 397-402. https://doi.org/10.1016/0038-092X(84)90191-9
Wallace JM, Hobbs PV. 2006. Atmospheric science an introductory survey. Academic Press, London.

Willmott CJ. 1982. Some comments on the evaluation of model performance. Bulletin of the American Meteorological Society 63, 1309-1313. https://doi.org/10.1 175/1520-0477(1982)063<1309:SCOTEO >2.0.CO;2 